\section{Interposition arthroplasty of temporomandibular joint ankylosis using temporalis muscle flap: our experience}

\author{
Nilam U. Sathe, Prsad Bhange, \\ Rumita Acharya, Abhijeet Bhatia, \\ Shashikant Mashal \\ Ent Department, Seth G.S Medical \\ College \& Kem Hospital, Mumbai, India
}

Abstract

Ankylosis is defined as loss of joint movement resulting from fusion of bones within the joint or calcification of the ligaments around it. Satisfactory surgical correction of temporomandibular joint (TMJ) ankylosis is limited by a high recurrence rate. This study aims to show that interposition arthroplasty with temporalis muscle flap improves mouth opening in 6 patients with TMJ ankylosis. Six patients with TMJ ankylosis were treated by interposition arthroplasty. The patients were evaluated between ten and 18 months after surgery. Preand postoperative assessment included a thorough analysis of case history and a physical examination to determine the cause of ankylosis, the maximal incisal opening and type of the ankylosis, recurrence rate and presence of facial nerve paralysis. All 6 patients had unilateral involvement. The mean age was 12.5 years \pm 6.5 (range 6 - 19 years). The mouth incisal opening in the preoperative period ranged from $5 \mathrm{~mm}$ to $11 \mathrm{~mm}$ and in the postoperative period it ranged from $30 \mathrm{~mm}$ to $35 \mathrm{~mm}$. No recurrence and no facial palsy were observed in our series. No recurrence was noted, and in all the cases there was type IV ankylosis. Trauma was the major cause of temporomandibular joint ankylosis in our sample. Interpositional arthroplasty is a highly effective and safe surgical management option for TMJ ankylosis with acceptable immediate and long-term outcome, particularly when temporalis fascia and muscle are used.

\section{Introduction}

The temporomandibular joint (TMJ) is a synovial joint formed between the mandibular condyle and the articular fossa of the temporal bone. It is the joint that allows mastication and speech. ${ }^{1}$ TMJ ankylosis is an intracapsular union of the disc-condyle complex to the temporal articular surface that restricts mandibular movements, causing the fibrous adhesions or bony fusion between condyle, disc, glenoid fossa, and eminence. ${ }^{2}$ It may cause problems in mastication, digestion, speech, appearance and hygiene, bird face deformity, and facial asymmetry aggravating psychological stress. ${ }^{3}$ In growing patients, deformities of the mandible and maxilla may occur together with malocclusion. ${ }^{4,5}$ It is most commonly associated with trauma (13-100\%), local or systemic infection (10-50\%), or systemic disease (10\%), such as ankylosing spondylitis, rheumatoid arthritis, or psoriasis. ${ }^{6,7}$ Ankylosis can also occur as a result of TMJ surgery. ${ }^{8}$ More unusual causes include rheumatoid arthritis, ${ }^{9}$ sickle cell anemia ${ }^{10}$ and fibrodysplasia ossificans progressiva. ${ }^{11}$ A variety of techniques for its treatment have been described in the literature. Several authors have studied and developed different techniques; however, no single method has produced uniformly successful results, and in the treatment of TMJ ankylosis recurrence still remains the major problem. Inadequate exposure of the TMJ region (Figures 1 and 2) because of adjacent structures (facial nerve, carotid, jugular and maxillary vessels) often leads to insufficient removal of the ankylotic bone, thus leading to a recurrence of the problem..$^{12}$ Surgical options for treatment include gap arthroplasty which is still preferred by some authors ${ }^{13}$ and interpositional surgery which is the standard procedure.$^{14-16} \mathrm{~A}$ range of materials is used for interpositional surgery including temporalis fascia, temporalis muscle, masseter muscle, fascia lata, dermis, full thickness skin, and autologous costochondral cartilage. Non-biological options are insertion of silastic materials and T-plate insertion. ${ }^{14-19}$

The present study describes our experience with interpositional arthroplasty using temporalis muscle flap in TMJ ankylosis of 6 patients with primary ankylosis during a period of three years. These 6 cases were treated with condylectomy with interposition arthroplasty with temporalis fascia flap.

The aim of this paper is to show that interposition arthroplasty with temporalis fascia flap in the treatment of TMJ ankylosis improves mouth opening and prevents recurrence.

\section{Materials and Methods}

This is a clinical study carried out from 2007 to 2010. All 6 cases had neglected, overlooked, post-traumatic and post-infectious TMJ ankylosis. Data were collected on the maximum mouth opening, the etiology, the type of ankylosis, treatment, recurrences, and facial nerve injuries. Measurements of maximal interincisal opening (MIO), lateral movements and protrusion were made the day before the surgical procedure. Inter incisor distance was recorded by using vernier caliper. Examination
Correspondence: Nilam U. Sathe,

Yash.Co.0p.Society, 66/1748, Kannamwar Nagar Vikhroli (East), Mumbai 400083, India

Tel. +91.022 .257 .828 .01 - Cell: +91.982 .130 .9298 .

E-mail: drneelam_s@yahoo.co.in

Key words: interposition arthroplasty, temporomandibular joint ankylosis

Acknowledgments: we thank our Dean and Director of Medical Education and Major Hospitals Dr. Sanjay Oak for permitting us to publish this paper.

Received for publication: 13 June 2011.

Accepted for publication: 19 September 2011.

This work is licensed under a Creative Commons Attribution NonCommercial 3.0 License (CC BYNC 3.0).

(C) Copyright N.U. Sathe et al., 2011

Licensee PAGEPress, Italy

Surgical Techniques Development 2011; 1:e19 doi:10.4081/std.2011.e19

included panoramic X-rays and computerized axial tomogram to determine the anatomic boundaries and type of ankylosis. All patients underwent surgery for TMA; interpositioning materials used during surgery included temporalis fascia, temporalis muscle. Operative findings regarding the TMA were recorded. Drains were removed on the $3^{\text {rd }}$ to $6^{\text {th }}$ day post surgery. Mouth opening exercises were started after drain removal. Patients were discharged after an average 5-7 days. Stitches were removed after 7-10 days. Follow-up recommendations included mouth opening exercises for six months. Post-operative assessment for jaw movements and complications were performed as during the preoperative stage. Follow-up assessment was performed at one month, three months and six months; further follow up was carried out for up to 18 months (range 10-18 months) (Figures 3 and 4).

Of the 6 study subjects, 3 were males (50\%) and 3 females (50\%). All patients (100\%) had unilateral involvement. Preoperative CT scans revealed bony ankylosis in all 6 , and this diagnosis was confirmed when the joint was exposed during surgery. Interposition arthroplasty was carried out in all patients using Alkayat Bramley incision with Papowich Crane modification with pedicled temporal fascia as an interposition material. The most common age group was from six to 19 years of age. In most cases, history of trauma was confirmed more than four years previously. The majority of cases $(66.6 \%)$ were post traumatic and a history of a fall from a height was reported; $33.3 \%$ cases were post infectious.

\section{Anesthesia}

The administration of anesthesia to 
patients with TMJ ankylosis is a challenge because securing the airway can be very difficult. It requires considerable expertise and adequate monitoring facilities. The safest technique for securing the airway would be a nasal fiberoptic assisted intubation with the patient awake under local anesthesia.

\section{Procedure}

The mainstay of surgical access is the preauricular approach when the incision is placed just in front of the tragus with a small superior component at the temporal hair-baring region (Alkayat Bramley Incision with Papowich Crane modification). In order to achieve an inconspicuous scar, the inferior limb of incision could rest on the rim of tragus skin or be placed total endaurally. In case of extensive exposure of the periarticular complex or the need for temporal muscle flap harvesting, temporal extension or even coronal incision for bilateral procedure is sometimes necessary. Oblique incision to the superficial layer of the deep temporal fascia to avoid injury to the temporal branch of the facial nerve was described by Al-Kayat and Bramley for skin flap reflection. Meticulous dissection of joint space is best achieved under magnification for thorough examination of the status of the articulating disc (Figures 5 and 6).

Coronoidectomy on the ipsilateral side was performed for all 6 surgical procedures. The contralateral coronoidectomy was performed in 3 cases. After bony ankylosis resection, reconstruction with temporal muscle/facial flap (interposition arthroplasty) performed using pedicled temporal fascia is the immediate available local flap of choice. Medial retraction is of utmost importance in TMJ surgery, especially during bony ankylosis resection, to avoid devastating complications that might occur involving vital skull base structures, such as the internal carotid artery, or cranial fossa perforation.

\section{Results}

Before surgery, the mouth opening (inter incisor distance) ranged from $5 \mathrm{~mm}$ to $11 \mathrm{~mm}$ and in the postoperative period from 30 to 35 $\mathrm{mm}$. Lateral and protrusive movements were severely restricted and preoperative assessment was not made in all patients. Postoperative satisfaction and adequate mouth opening was achieved; this was $30 \mathrm{~mm}$ to 31 $\mathrm{mm}$ in almost all cases at six months and more than $34 \mathrm{~mm}$ in 4 cases at one-year follow up. All patients had temporalis myofascial flap as the interpositional material. The postoperative period was uneventful in all cases. None of the cases reported recurrences or facial palsy Tables 1, 2 and 3).

\section{Discussion}

The main causes of TMJ ankylosis are trauma and infection. ${ }^{6-8}$ Estimates of a traumatic origin range from $26 \%$ to $75 \%$ and of infection from $44 \%$ to $68 \%$. Roychoudhury et al. ${ }^{3}$ retrospectively studied 50 cases of TMJ ankylosis and showed that trauma was documented as a major etiological factor in $86 \%$ of all these cases. In the present study, the main causes were also trauma (66.6\%) and infection (33.3\%). TMJ ankylosis not only affects mouth opening but also the normal growth pattern of the mandible. Outcome of surgery for TMJ ankylosis is unpredictable. The type of ankylosis and patient age should be evaluated when
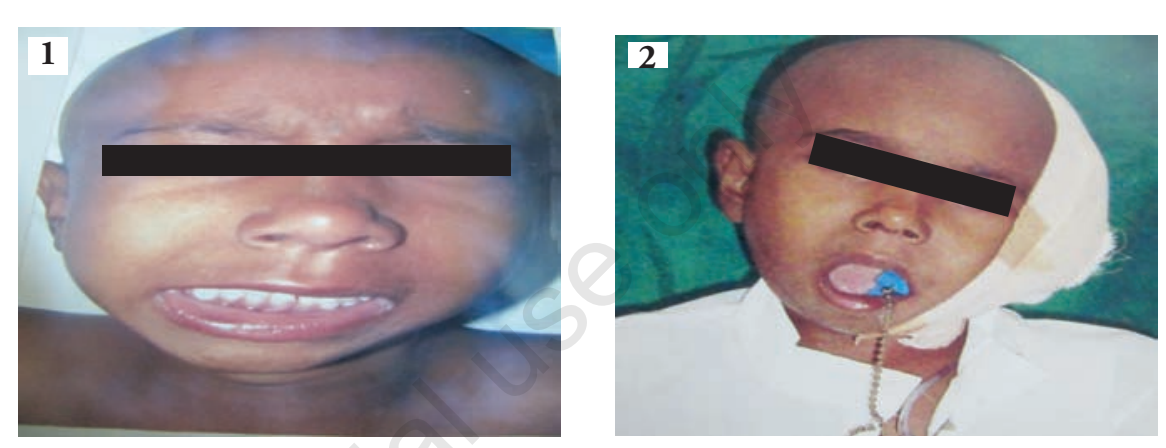

Figures 1 and 2. Preoperative photographs showing restricted mouth opening.
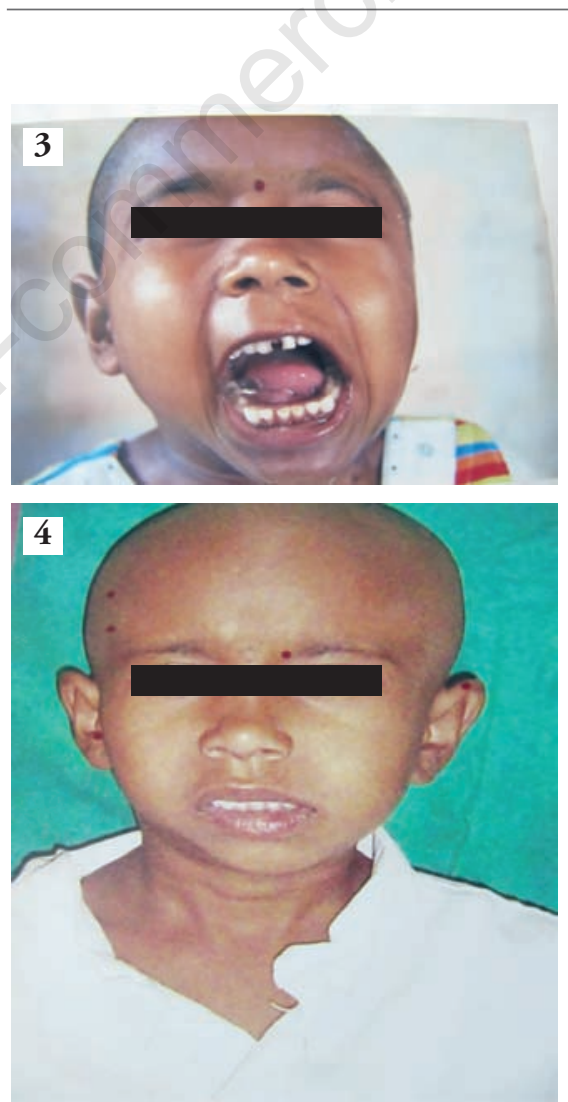

Figures 3 and 4. Postoperative photographs showing wide mouth opening. planning surgery. Care in the choice of surgical technique and of interposition material, and subsequent meticulous attention to long-term physiotherapy are considered essential to achieve a satisfactory result. ${ }^{20} \mathrm{~A}$ number of treatments for this condition have been described in the literature, including simple arthroplasty, interposition arthroplasty ${ }^{15}$ using temporal muscle fascia, ear cartilage or alloplastic material, and reconstruction of the joint using acrylic, titanium, or autogenous prostheses. ${ }^{21}$ However, there are possible disadvantages, such as morbidity at the donor site, muscle shrinkage and fibroses, a lack of fascia bulk, a tendency for the cartilage to fibrose and calcify, and unpredictable resorption when autogenous material is used. There is also the risk of
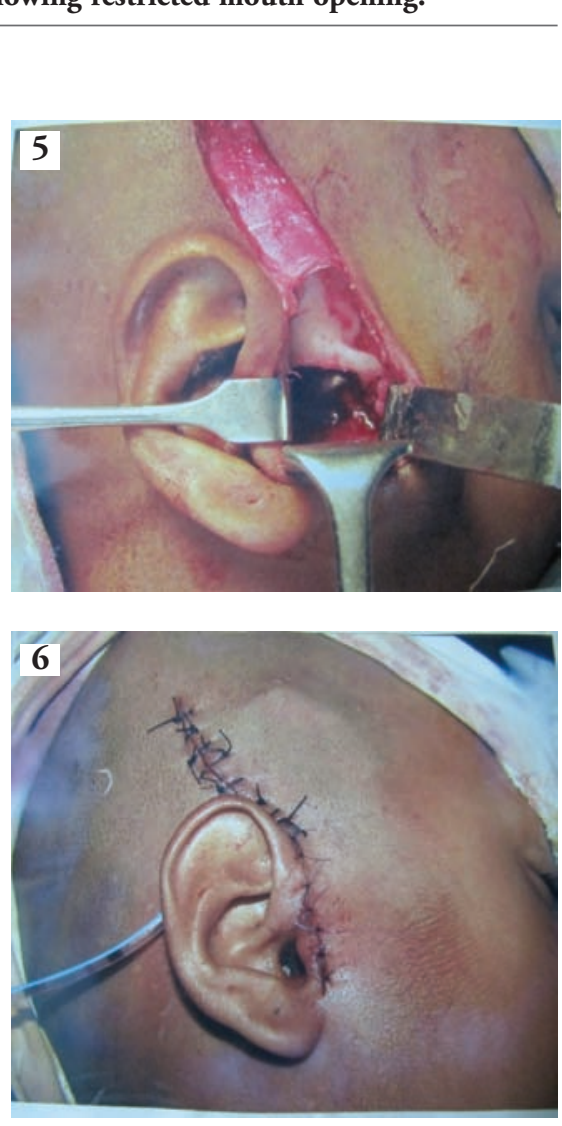

Figures 5 and 6. Intraoperative photographs showing TM joint ankylosis and wound closure. 
a foreign body reaction and degeneration and fibrosis over time, resulting in reankylosis when alloplastic material is used. ${ }^{10,22}$ Thus, at present, there is no ideal interpositional graft. ${ }^{15}$ According to Valentini et al., ${ }^{14}$ interpositional arthroplasty with the use of silastic allograft is associated with an increased persistence of local symptoms and a higher risk of foreign body granuloma, favoring ankylosis and relapse, and hindering rehabilitation. Irrespective of the technique chosen by the surgeon, aggressive resection of the bony or fibrous ankylotic segment is crucial to avoid recurrence. In addition, dissection of the muscles of the mandibular ramus and ipsilateral coronoidectomy must be performed to prevent inadequate intraoperative interincisal opening, because the coronoid process may be elongated in long-standing cases. ${ }^{23}$ If a $35 \mathrm{~mm}$ opening (for adults) without force is not achieved, a contralateral intraoral coronoidectomy should be performed. After that, aggressive physiotherapy should be recommended in order to disrupt and prevent adhesions, prevent soft-tissue contractions, and redevelop normal muscle function. ${ }^{23,24}$ Early mobilization may provoke bleeding and create a large hematoma, resulting in delayed healing and an increased likelihood of wound breakdown, disorganization and ossification. ${ }^{8}$ Kaban described a protocol for the treatment of TMJ ankylosis which consists of aggressive resection, ipsilateral coronoidectomy, contralateral coronoidectomy if needed, interposition with temporal fascia or cartilage, movement as soon as possible, and aggressive physical therapy. ${ }^{8}$ Abul Hassan ${ }^{25}$ concluded that deep temporal fascia is supplied by the middle temporal artery, a constant branch of superfi- cial temporal artery. Temporalis fascia flap is a locally available axial pattern flap, easy to elevate and available in all clinical situations. This vascularized flap has fewer chances of subsequent absorption and fibrosis regardless of the surgical approach used to gain access to the TMJ; the final dissection risks causing damage to the facial nerve. The incidence of complications, such as permanent injury of the facial nerve, is very low. ${ }^{26}$ The approach described by Alkayat and Bramley ${ }^{27}$ and Papowitch Crane incision when properly performed, may decrease the risk of damaging the facial nerve. Although our study was small, the results were in favor of temporal fascia as an interposition material. Therefore, in our opinion, it is the best method to prevent recurrence and improve mouth opening in cases of TMJ ankylosis.

\section{Conclusions}

Table 1. Ankylosis characteristics according to age of onset, age at surgery, sex, etiology, involvement, side of involvment.

\begin{tabular}{lllllll} 
N. & Age at onset & Age at surgery & Sex & Etiology & $\begin{array}{l}\text { Ankylosing } \\
\text { type }\end{array}$ & $\begin{array}{l}\text { Side of } \\
\text { involvement } \\
\text { of TM joint }\end{array}$ \\
\hline 1 & 3 years & 10 years & Male & Trauma & Bony type IV & Right \\
\hline 2 & 5 years & 10 years & Female & Trauma & Bony type IV & Right \\
\hline 3 & 7 years & 11 years & Male & Infection & Bony type IV & Right \\
4 & 11 years & 19 years & Female & Trauma & Bony type IV & Right \\
\hline 5 & 3 years & 6 years & Male & Infection & Bony type IV & Left \\
6 & 4 years & 6 years & Female & Trauma & Bony type IV & Left \\
\hline
\end{tabular}

Table 2. Ankylosis characteristics according to treatment, type of graft, follow up, recurrence rate and nerve injury after surgery.

\begin{tabular}{llccc} 
Treatment & Type of graft & $\begin{array}{c}\text { Postoperative } \\
\text { facial palsy }\end{array}$ & $\begin{array}{c}\text { Postoperative } \\
\text { follow up }\end{array}$ & $\begin{array}{c}\text { Recurrence of } \\
\text { ankylosis }\end{array}$ \\
$\begin{array}{l}\text { Interposition } \\
\text { arthroplasty }\end{array}$ & $\begin{array}{l}\text { Temporalis myofascial } \\
\text { muscle flap }\end{array}$ & No & 12 months & No \\
$\begin{array}{l}\text { Interposition } \\
\text { arthroplasty }\end{array}$ & $\begin{array}{l}\text { Temporalis myofascial } \\
\text { muscle flap }\end{array}$ & No & 18 months & No \\
\hline $\begin{array}{l}\text { Interposition } \\
\text { arthroplasty }\end{array}$ & $\begin{array}{l}\text { Temporalis myofascial } \\
\text { muscle flap }\end{array}$ & No & 10 months & No \\
$\begin{array}{l}\text { Interposition } \\
\text { arthroplasty }\end{array}$ & $\begin{array}{l}\text { Temporalis myofascial } \\
\text { muscle flap }\end{array}$ & No & 18 months & No \\
\hline $\begin{array}{l}\text { Interposition } \\
\text { arthroplasty }\end{array}$ & $\begin{array}{l}\text { Temporalis myofascial } \\
\text { muscle flap }\end{array}$ & No & 16 months & No \\
$\begin{array}{l}\text { Interposition } \\
\text { arthroplasty }\end{array}$ & $\begin{array}{l}\text { Temporalis myofascial } \\
\text { muscle flap }\end{array}$ & No & 12 months & No \\
\hline
\end{tabular}

Table 3. Preoperative and postoperative measurement of mouth opening.

\begin{tabular}{cccc} 
N. & $\begin{array}{c}\text { Post operative } \\
\text { follow up }\end{array}$ & $\begin{array}{c}\text { Maximum mouth } \\
\text { opening: preoperative }\end{array}$ & $\begin{array}{c}\text { Maximum mouth } \\
\text { opening: postoperative }\end{array}$ \\
1 & 18 months & $8 \mathrm{~mm}$ & $30 \mathrm{~mm}$ \\
2 & 12 months & $7 \mathrm{~mm}$ & $34 \mathrm{~mm}$ \\
\hline 3 & 10 months & $5 \mathrm{~mm}$ & $35 \mathrm{~mm}$ \\
4 & 18 months & $7 \mathrm{~mm}$ & $32 \mathrm{~mm}$ \\
\hline 5 & 16 months & $8 \mathrm{~mm}$ & $35 \mathrm{~mm}$ \\
6 & 12 months & $11 \mathrm{~mm}$ & $34 \mathrm{~mm}$ \\
\hline
\end{tabular}

The results of our study have shown that there was adequate mouth opening with no recurrence in patients in whom temporalis fascia was used as an interpositional material in a follow up of 10-18 months. We conclude that interposition arthroplasty, especially with temporal fascial flap interposition, is a good treatment option to prevent recurrence and improve mouth opening in cases of TMJ ankylosis.

\section{References}

1. Abbas I, Jamil M, Jehanzeb M, et al. Temporomandibular Joint Ankylosis: Experience with Interpositional Gap Arthroplasty at Ayub Medical College Abbottabad. J Ayub Med Coll Abbottabad 2005; 17.

2. Long X, Li X, Cheng Y, et al. Preservation of disc for treatment of traumatic temporomandibular joint ankylosis. J Oral Maxillofac Surg 2005;63:897-902.

3. Roychoudhury A, Parkash H, Trikha A. Functional restoration by gap arthroplasty in temporomandibular joint ankylosis: A report of 50 cases. Oral Surg Oral Med Oral Pathol 1999;87:166-9.

4. Miyamoto H, Kurita K, Ogi N, et al. The role of the disk in sheep temporomandibular joint ankylosis. Oral Surg Oral Med Oral Pathol 1999;88:151-8.

5. Raveh J, Vuillemin T, Lädrach K, et al. Temporomandibular joint ankylosis: surgical treatment and long-term results. J Oral Maxillofac Surg 1989;47:900-6.

6. Gay-Escoda C, Arguero M. La corrección quirúrgica de la anquilosis de la articulación temporomandibular. Descripción de 
siete casos. Avances en Odontoestomatología 1994;10:74.

7. Kaban L, Pogrel MA, Perrott DH. Complications in oral and maxillofacial surgery. 1st ed. Philadelphia: WB Saunders 1997:265-77.

8. Kaban LB, Perrott DH, Fisher K. A protocol for management of temporomandibular joint ankylosis. J Oral Maxillofac Surg 1990;48:1145-51.

9. Kobayashi R, Utsunomiya T, Yamamoto H, et al. Ankylosis of the temporomandibular joint caused by rheumatoid arthritis: a pathological study and review. J Oral Sci 2001;43:97-101.

10. Baykul T, Aydin MA, Nasir S. Avascular necrosis of the mandibular condyle causing fibrous ankylosis of the temporomandibular joint in sickle cell anemia. $\mathrm{J}$ Craniofac Surg 2004;15:1052-6.

11. Herford AS, Boyne PJ. Ankylosis of the jaw in a patient with fibrodysplasia ossificans progressiva. Oral Surg Oral Med Oral Pathol Oral Radiol Endod 2003;96:680-4.

12. Raveh J, Vuillemin T, Lädrach $\mathrm{K}$, et al. Temporomandibular joint ankylosis: surgical treatment and long-term results. J Oral Maxillofac Surg 1989;47:900-6.

13. Devgan A, Siwach RC, Sangwan SS. Functional restoration by excision arthroplasty in temporomandibular joint ankylo- sis--a report of 35 cases. Indian J Med Sci 2002;56:61-4.

14. Valentini V, Vetrano S, Agrillo A, et al. Surgical treatment of TMJ ankylosis: our experience (60 cases). J Craniofac Surg 2002;13:59-67.

15. Su-Gwan K. Treatment of temporomandibular joint ankylosis with temporalis muscle and fascia flap. Int $\mathrm{J}$ Oral Maxillofac Surg 2001;30:189-93.

16. Saeed NR, Kent JN. A retrospective study of the costochondral graft in TMJ reconstruction. Int $\mathrm{J}$ Oral Maxillofac Surg 2003;32:606-9.

17. Liu G, Li Z, Dong Y. Autogenous costochondral graft applied in the reconstruction of the temporomandibular joint. Zhonghua Zheng Xing Wai Ke Za Zhi 2000;16:163-5.

18. Demir Z, Velidedeoglu H, Sahin U, et al. Preserved costal cartilage homograft application for the treatment of temporomandibular joint ankylosis. Plast Reconstr Surg 2001;108:44-51.

19. Balaji SM. Modified temporalis anchorage in craniomandibular reankylosis. Int $\mathrm{J}$ Oral Maxillofac Surg 2003;32:480-5.

20. Manganello-Souza LC, Mariani PB. Temporomandibular joint ankylosis: Report of 14 cases. Int J Oral Maxillofac Surg 2003;32:24-9.

21. Erdem E, Alkan A. The use of acrylic mar- bles for interposition arthroplasty in the treatment of temporomandibular joint ankylosis: follow up of 47 cases. Int J Oral Maxillofac Surg 2001;30:32-6.

22. Matsuura H, Miyamoto H, Ogi N, et al. The effect of gap arthroplasty on temporomandibular joint ankylosis: an experimental study. Int J Oral Maxillofac Surg, 2001; 30:431-7.

23. House JW, Brackmann DE. Facial nerve grading system. Otolaryngol Head Neck Surg 1993:146-7.

24. Qudah MA, Qudeimat MA, Al-Maaita J. Treatment of TMJ ankylosis in Jordanian children - a comparison of two surgical techniques. J Craniomaxillofac Surg 2005; 3330-6.

25. Abul-Hassan HS, von Drasek Ascher G, Acland RD. Surgical anatomy and blood supply of the fascial layers of the temporal region. Plast Reconstr Surg 1986;77:17-28.

26. Güven 0 . Treatment of temporomandibular joint ankylosis by a modified fossa prosthesis. J Craniomaxillofac Surg 2004; 32:236-42.

27. Hall MB, Brown RW, Lebowitz MS. Facial nerve injury during surgery of the temporomandibular joint: a comparison of two dissection techniques. J Oral Maxillofac Surg 1985;43:20-3. 